\title{
Pedagogia de Projetos: Uma Ferramenta para a Aprendizagem
}

\author{
José Demontier Guedes ${ }^{1}$; Antonielle Serafim de Souza ${ }^{2}$; Francisca Maraysa Luciano Sidrim ${ }^{3}$; \\ Quenilda Fernandes de Oliveira Lima ${ }^{3}$
}

\begin{abstract}
Resumo: Esse artigo faz uma introdução ao tema Pedagogia de Projetos abordando a possibilidade de reconhecêla como um caminho inovador para o processo de ensino-aprendizagem. Tem como objetivo possibilitar a formação de alunos reflexivos, participativos e atuantes em um mundo informatizado e globalizado. O estudo baseou-se em uma pesquisa exploratória, tendo a bibliográfica como técnica para coleta de dados visando perceber como o trabalho com projetos vem sendo inserido no contexto educacional, além de constituir uma interessante fonte de pesquisa para o professor que busca resignificar a sua prática na escola.
\end{abstract}

Palavras-chave: Educação. Projetos. Aprendizagem.

\section{Pedagogy of Projects: a Tool for Learning}

\begin{abstract}
This article makes an introduction to the theme of Project Pedagogy, addressing the possibility of recognizing it as an innovative path for the teaching-learning process. Its objective is to enable the formation of reflexive, participatory and active students in a globalized and computerized world. The study was based on an exploratory research, having the bibliographical as a technique for data collection aiming to perceive how the work with projects has been inserted in the educational context, besides being an interesting source of research for the teacher who seeks to re-establish their practice in school.
\end{abstract}

Keywords: Education. Projects. Learning.

\section{Introdução}

A educação engloba diversos processos mediante os quais o ser humano se capacita para que possa ser responsável pela sua manutenção e perpetuação, dentro dos modos culturais de ser, estar e agir, que é necessário à convivência e ao ajustamento para viver em sociedade.

Diante desses processos, pode-se destacar que a educação abrange vários fatores bem como à questão social, política e ensino educacional que se relacionam para construir uma sociedade capaz de assumir concepções coerentes, articuladas, explícitas e ativas com a intenção de sair do senso comum para uma consciência crítica.

\footnotetext{
${ }^{1}$ Orientador. Mestre em Ciências da Educação. Psicólogo. Pedagogo. Professor do Instituto Dom José de Educação e Cultura - IDJ. Autor Correspondente - E-mail: proerddemontierguedes@gmail.com

${ }^{2}$ Licenciada e Bacharel em Ciências Biológicas (Universidade Regional do Cariri - URCA); Pós-Graduada em Gestão Escolar com ênfase em Psicopedagogia (Universidade Doutor Leão Sampaio - UniLeão); Graduanda em Pedagogia (Universidade Vale do Acaraú - UVA). ${ }^{3}$ Graduanda em Pedagogia (Universidade Vale do Acaraú - UVA).
} 
A necessidade de reformular as relações de ensino-aprendizagem promovidas pela escola vem estimulando os educadores a desenvolverem iniciativas pedagógicas diferenciadas. O ensino por projetos tem sido uma entre tantas estratégias pedagógicas experimentadas para dinamizar o processo de ensino-aprendizagem, restituindo ao educando o papel de investigador, o prazer da descoberta e a satisfação pelo ato de aprender.

A educação de qualidade é um direito de todos, oportuniza e insere o indivíduo nos modos sociais e culturais aprimorando e potencializando os seus conhecimentos para viver em sociedade, assim sendo torna-se fundamental inovar no campo educacional. Nesse sentido, o artigo tem como objetivo conhecer a práxis da Pedagogia de Projetos de modo a compreender suas contribuições para o processo de ensino- aprendizagem, bem como apresentar os conceitos relacionados e suas reais aplicações no cenário educacional com o propósito de auxiliar professores, escolas, pais e sociedade como um todo.

A pedagogia de projetos é um meio de inovar no campo educacional? Ela garante a aprendizagem significativa?

O trabalho com a metodologia dos projetos somente se justifica quando os alunos colocam seu interesse e sua energia na busca de temas relevantes, essenciais para a aprendizagem no programa da disciplina. O ideal é que a escolha dos temas se desenvolva no consenso entre a orientação do professor e a curiosidade dos alunos. (ANTUNES, 2012, p. 87)

O método por projetos propõe que os saberes escolares estejam integrados com os saberes sociais, pois ao estudar o aluno sentirá que está aprendendo algo que faz sentido e tem significado em sua vida, assim compreende o seu valor e desenvolve uma postura indispensável para a resolução de problemas sociais se permitindo como sujeito cultural.

Hernandez (1998) descreve a importância de trabalhar com projetos e o que ele pode permitir.

Aproxima-se da identidade dos alunos e favorecer a construção da subjetividade, longe de um prisma paternalista, gerencial ou psicologista, o que implica considerar que a função da escola não e apenas ensinar conteúdos, nem vincular a instrução coma aprendizagem. Revisar a organização do currículo por disciplinas e a maneira de situálo no tempo e no espaço escolar. O que torna necessária a proposta de um currículo que não seja uma representação do conhecimento fragmentada, distanciada dos problemas que os alunos vivem e necessitam responder em suas vidas, mas, sim, 
solução de continuidade. Levar em conta o que acontece fora da escola, nas transformações sociais e nos saberes, a enorme produção de informação que caracteriza a sociedade atual e aprender a dialogar de uma maneira critica com todos esses fenômenos (HERNANDEZ,1998, p.61).

Nota-se então o desafio que se coloca diante das instituições escolares: a busca fervorosa de alternativas de ensino mais abertas e próximas dos alunos. Nesta corrida, a pedagogia de projetos tem sido uma expressão constantemente presente no âmbito escolar, refletindo os anseios (já bem antigos) de uma educação libertadora.

Nas discussões educacionais o perfil do sujeito que as escolas precisam formar numa sociedade globalizada e mutável como a nossa está constantemente em pauta. Tornou-se exigência a formação do sujeito crítico e consciente de seu papel nas mudanças sociais que ocorrem a cada segundo. $\mathrm{O}$ advento de novas tecnologias de comunicação e informação, que se posicionam como mediadores entre o sujeito e o saber, instiga um novo olhar para o processo ensino-aprendizagem que já não se satisfaz apenas com o conhecimento transmitido pelo professor, mas construído pelos alunos a partir de suas relações com a cultura, a ciência e a tecnologia. A educação "bancária" (FREIRE, 1987) perde seu espaço para a formação do sujeito global, investigador, curioso, autônomo e responsável pela sua aprendizagem.

Temos então a redefinição do papel de três importantes agentes no contexto educacional: o conhecimento, tido como bem de valor; o sujeito, principal responsável pela construção do seu saber e o professor, mediador entre os dois primeiros. Esta redefinição atribui ao processo ensino- aprendizagem características inovadoras: participação ativa dos alunos no planejamento e execução de suas atividades, utilização de novos recursos de ensino, concepção do professor pesquisador e eterno aprendiz, a ênfase na participação da família na formação dos alunos. Nota-se então o desafio que se coloca diante das instituições escolares: a busca fervorosa de alternativas de ensino mais abertas e próximas dos alunos. Nesta corrida, a pedagogia de projetos tem sido uma expressão constantemente presente no âmbito escolar, refletindo os anseios (já bem antigos) de uma educação libertadora.

A Pedagogia de Projetos pode oferecer uma estratégia de construção de identidades, uma vez que o aluno perceba que o projeto será uma ocasião de conquistar um maior reconhecimento social, o que afeta positivamente sua identidade e conceito de cidadania. 
Id on Line Revista Multidisciplinar e de Psicoloqia

Id on Line Multidisciplinary and Psycology Journal

A disseminação dos estudos acerca dos trabalhos com projeto não coloca a prática como uma solução definitiva a todos os problemas mas sim como uma ferramenta de apoio ao processo educativo e ao desenvolvimento da ciência.

\section{Conceito de Projeto}

A palavra "projeto" aparece em campos diferentes como expressões múltiplas bem características da época atual: projeto de pesquisa; projeto de vida; projeto da instituição; projeto pedagógico da escola; projeto de instalação profissional; etc.

Trabalhar com projetos faz parte do senso comum nas mais variadas áreas, desde as técnicas até as humanas, seja no espaço público, privado ou acadêmico/científico. Qualquer iniciativa de cunho profissional, pessoal ou associativo passa, inevitavelmente, pelo esboço de um projeto. Fala-se de projetos políticos de uma nação, de projetos político/pedagógicos de escolas, de homens e mulheres construindo seus projetos de vida pessoal e profissional.

A ideia de projeto envolve a antecipação de algo desejável que ainda não foi realizado, traz a ideia de pensar uma realidade que ainda não aconteceu. O processo de projetar implica analisar o presente como fonte de possibilidades futuras (Freire \& Prado,1999). Tal como vários autores colocam, a origem da palavra "projeto" deriva do latim projectus, que significa "algo lançado para frente". A ideia de projeto é própria da atividade humana, da sua forma de pensar em algo que deseja tornar real, portanto, o "projeto é inseparável do sentido da ação" (ALMEIDA, 2002). Neste sentido, Barbier (In: Machado, 2000) salienta que "o projeto não é uma simples representação do futuro, do amanhã, do possível, de uma ideia, é o futuro a fazer, um amanhã a concretizar, um possível a transformar em real, uma ideia a transformar em acto".

No entanto, o ato de projetar requer abertura para o desconhecido, para o não determinado e flexibilidade para reformular as metas à medida que as ações projetadas evidenciam novos problemas e dúvidas.

Atualmente, afirma Nogueira (2001), boa parte das escolas trabalham ou dizem trabalhar por projetos. A falta de conhecimento sobre essa prática tem levado muitos professores a chamar de "projetos" quaisquer atividades que resultem na elaboração de cartazes, 
Id on Line Revista Multidisciplinar e de Psicologia

Id on Line Multidisciplinary and Psycology Journal

visitas, jogos, festas escolares, numa visão reducionista da verdadeira amplitude e organização didático/pedagógica que o assunto requer.

Dentro dessa perspectiva é válido aprofundar-se no estudo, tecer considerações acerca de sua veiculação no campo educacional e as implicações com o currículo escolar e a construção do conhecimento, sem desmerecer as influências sofridas dos contextos geo/sócio/econômicos de todos os matizes.

\section{A Pedagogia de Projetos: Um novo significado para a Metodologia e a Aprendizagem}

\section{Estudo do termo}

O termo "Pedagogia de Projetos" passou a ser conhecida no Brasil com a divulgação do movimento chamado Escola Nova. Este movimento veio contrapor o sistema de escola tradicionalista e até hoje gera muita controvérsia no meio educacional. A Pedagogia de Projeto não é um modelo pedagógico ou uma metodologia de ensino e sim um movimento que foi resultado de pesquisas de educadores europeus como Montessori, Decroly, e outros, e na América do Norte seus representantes foram John Dewey e William Kilpatrick. Foram eles que criaram o chamado "Método de Projetos" e suas propostas pedagógicas foram introduzidas e disseminadas no Brasil por Anísio Teixeira e Lourenço Filho.

A ideia principal da Pedagogia de Projetos ou também conhecida como Pedagogia por Projetos é fazer com que o ator principal do processo ensino/aprendizagem, o alunado, participe com mais afinco de todo este processo de construção do conhecimento. Este conceito assemelha-se muito à teoria construtivista de Piaget onde ele afirma que o indivíduo constrói e produz o conhecimento através da interação com o ambiente em que ele vive e que esta interação propicia o desenvolvimento da aprendizagem.

Diante das transformações que vêm ocorrendo na sociedade moderna, a concepção de escola e sua função social precisa ser revista, repensada, pois a educação autoritária, compartimentada, com currículo fragmentado e distanciado das transformações sociais e das vidas dos alunos, onde o sujeito educando não tem autonomia e participação na construção de 
seus saberes, está perdendo seu significado. Esse modelo de escola vem sendo questionado o que leva a necessidade de mudança de paradigmas voltados para um ensino/aprendizagem que considerem os objetivos dos indivíduos frente a essa nova sociedade.

Em meio a essa crise de identidade e função social da escola, começam a surgir novas reflexões e concepções de educação que devolvam à escola o seu papel de espaço educativo e de transformação social, visando recuperar os laços entre educação escolar significativa e a prática social, conciliando aprendizagem escolar com uma formação mais integral.

É nesse contexto que a discussão sobre Pedagogia de Projetos, hoje, se coloca. Isso significa que é uma discussão sobre uma postura pedagógica e não sobre uma técnica de ensino mais atrativa para os alunos.

O trabalho por projetos suscita nos educandos a formação de indivíduos capazes de atuarem na sociedade de maneira participativa, crítica, reflexiva, autônoma, solidária e muitas outras necessárias à formação integral que contribua não só para a vida escolar (preparação para a vida futura) como também para a vida social do educando (que acontece no momento presente).

De acordo com o artigo $1^{\circ}$, parágrafo $2^{\circ}$ da Lei de Diretrizes e Bases da Educação Nacional - LDBN (1996), “a educação escolar deverá vincular-se ao mundo do trabalho e à prática social”.

Em outras palavras pode-se dizer que a Pedagogia de Projetos é a construção de uma prática pedagógica centrada na formação global dos alunos uma vez que traduzem uma visão diferente do que seja conhecimento e currículo e representam outra maneira de organizar o trabalho na escola.

Caracterizam-se pela forma de abordar um determinado tema ou conhecimento, permitindo uma aproximação da identidade e das experiências dos alunos, e um vínculo dos conteúdos escolares entre si e com os conhecimentos e saberes produzidos no contexto social e cultural, assim como com problemas que dele emergem. Dessa forma, eles ultrapassam os limites das áreas e conteúdos curriculares tradicionalmente trabalhados pela escola, uma vez que implicam o desenvolvimento de atividades práticas, de estratégias de pesquisa, de busca e uso de diferentes fontes de informação, de sua ordenação, análise, interpretação e representação. Implicam igualmente atividades individuais, de grupos/equipes e de turma(s), da escola, tendo 
Id on Line Revista Multidisciplinar e de Psicologia

Id on Line Multidisciplinary and Psycology Journal

em vista os diferentes conteúdos trabalhados (atitudinais, procedimentos, conceituais), as necessidades e interesses dos alunos.

Ao estudá-los, as crianças e os jovens realiza contato com o conhecimento não como algo pronto e acabado, mas como algo controverso. Um dos aspectos mais importantes, no trabalho como Projetos, é que ele permite que o aluno desenvolva uma atitude ativa e reflexiva diante de suas aprendizagens e do conhecimento, na medida em que percebe o sentido e o significado do conhecimento para a sua vida, para a sua compreensão do mundo.

$\mathrm{Na}$ pedagogia de projetos é necessário "ter coragem de romper com as limitações do cotidiano, muitas vezes autoimpostas" (ALMEIDA \& FONSECA JÚNIOR, 2000, p. 22) e “delinear um percurso possível que pode levar a outros, não imaginados a priori” (FREIRE \& PRADO, 1999, p. 113). Mas, para isto, é fundamental repensar as potencialidades de aprendizagem dos alunos para a investigação de problemáticas que possam ser significativas para eles e repensar o papel do professor nesta perspectiva pedagógica, inclusive integrando as diferentes mídias e outros recursos existentes no contexto da escola.

Para Moura (2010), trabalhar com projetos possibilita: o resgate do educando para o processo de ensino-aprendizagem (conhecimento) através de um processo significativo; a recuperação da autoestima positiva do educando; que o educando se reconheça como sujeito histórico; o desenvolvimento do raciocínio lógico, linguístico e a formação de conceitos; o desenvolvimento da capacidade de buscar e interpretar informações; a condução, pelo aluno, do seu próprio processo de aprendizagem; o desenvolvimento de atitudes favoráveis a uma vida cooperativa; a realização do ensino baseado na compreensão e na interdisciplinaridade; a proposta do trabalho por Projetos deve estar fundamentada numa concepção do educando como sujeito de direitos, ser social e histórico, participante ativo no processo de construção de conhecimentos; princípios éticos da autonomia, da responsabilidade, da solidariedade e do respeito ao bem comum; princípios políticos dos direitos e deveres de cidadania, do exercício da criticidade e do respeito à democracia; princípios estéticos e culturais da sensibilidade, da criatividade, da ludicidade e da diversidade das manifestações artísticas e culturais; o respeito à identidade e particularidades pessoais; a integração entre os aspectos físicos, emocionais, afetivos, cognitivos e sociais.

Com essas contribuições significativas do trabalho por Projetos o educando se insere de forma efetiva e prática na sociedade contemporânea. A educação e a prática educativa tornam- 
Id on Line Revista Multidisciplinar e de Psicologia

Id on Line Multidisciplinary and Psycology Journal

se fundamental para que o indivíduo alcance todas as condições necessárias para se tornar cidadão ativo. Com isso, a escola resgata e sustenta a sua.

\section{Pedagogia de Projetos: método ou postura pedagógica?}

A prática pedagógica por projetos não deve ser entendida como uma atividade meramente funcional, regular e metódica. A Pedagogia de Projetos não é um método, pois a ideia de método é de trabalhar com objetivos e conteúdos pré-fixados, pré-determinados, apresentando uma sequencia regular, prevista e segura, refere-se à aplicação de fórmulas ou de uma série de regras.

Trabalhar por meio de Projetos é exatamente o oposto, pois nele, o ensino-aprendizagem se realiza mediante um percurso que nunca é fixo, ordenado. $\mathrm{O}$ ato de projetar requer abertura para o desconhecido, para o não-determinado e flexibilidade para reformular as metas e os percursos à medida que as ações projetadas evidenciam novos problemas e dúvidas.

Fernando Hernández (1998) vem discutindo o tema e define os projetos de trabalho não como uma metodologia, mas como uma concepção de ensino, uma maneira diferente de suscitar a compreensão dos alunos sobre os conhecimentos que circulam fora da escola e de ajudá-los a construir sua própria identidade.

O trabalho por projetos requer mudanças na concepção de ensino e aprendizagem e, consequentemente, na postura do professor. Hernández (1988) enfatiza ainda que o trabalho por projeto não deve ser visto como uma opção puramente metodológica, mas como uma maneira de repensar a função da escola. Leite (1996) apresenta os Projetos de Trabalho não como uma nova técnica, mas como uma pedagogia que traduz uma concepção do conhecimento escolar.

Em se tratando dos conteúdos, a pedagogia de projetos é vista pelo seu caráter de potencializar a interdisciplinaridade. Isto de fato pode ocorrer, pois o trabalho com projetos permite romper com as fronteiras disciplinares, favorecendo o estabelecimento de elos entre as diferentes áreas de conhecimento numa situação contextualizada da aprendizagem.

A Pedagogia de Projetos é um meio de trabalho pertinente ao processo de ensinoaprendizagem que se insere na Educação promovendo-a de maneira significativa e 
compartilhada, auxiliando na formação integral dos indivíduos permeado pelas diversas oportunidades de aprendizagem conceitual, atitudinal, procedimental para os mesmos. Os projetos de trabalho não se inserem apenas numa proposta de renovação de atividades, tornando-as criativas, e sim numa mudança de postura que exige o repensar da prática pedagógica, quebrando paradigmas já estabelecidos.

Possibilita que os alunos, ao decidirem, opinarem, debaterem, construam sua autonomia e seu compromisso com o social, formando-se como sujeitos culturais e cidadãos.

Será necessário oportunizar situações em que os alunos participem cada vez mais intensamente na resolução das atividades e no processo de elaboração pessoal, em vez de se limitar a copiar e reproduzir automaticamente as instruções ou explicações dos professores. Por isso, hoje o aluno é convidado a buscar, descobrir, construir, criticar, comparar, dialogar, analisar, vivenciar o próprio processo de construção do conhecimento (ZABALA, 1998).

O fato de a pedagogia de projetos não ser um método para ser aplicado no contexto da escola dá ao professor uma liberdade de ação que habitualmente não acontece no seu cotidiano escolar. O compromisso educacional do professor é justamente saber O QUÊ, COMO, QUANDO E POR QUE desenvolver determinadas ações pedagógicas. E para isto é fundamental conhecer o processo de aprendizagem do aluno e ter clareza da sua intencionalidade pedagógica.

Mais do que uma técnica atraente para transmissão dos conteúdos, como muitos pensam, a proposta da Pedagogia de Projetos é promover uma mudança na maneira de pensar e repensar a escola e o currículo na prática pedagógica. Com a re-interpretação atual da metodologia, esse movimento tem fornecido subsídios para uma pedagogia dinâmica, centrada na criatividade e na atividade discentes, numa perspectiva de construção do conhecimento pelos alunos, mais do que na transmissão dos conhecimentos pelo professor.

\section{Analogia entre construtivismo e Pedagogia de Projetos}

O Construtivismo e a Pedagogia de Projetos tem em comum a insatisfação com um sistema educacional que teima em continuar essa forma particular de transmissão que consiste 
em fazer repetir, recitar, aprender, ensinar o que já está pronto, em vez de fazer agir, operar, criar, construir a partir da realidade vivida por alunos e professores, isto é, pela sociedade.

Na Pedagogia de Projetos a relação ensino/aprendizagem é voltada para a construção do conhecimento de maneira dinâmica, contextualizada, compartilhada, que envolva efetivamente a participação dos educandos e educadores num processo mútuo de troca de experiências. Nessa postura a aprendizagem se torna prazerosa, pois ocorre a partir dos interesses dos envolvidos no processo, da realidade em que estes estão inseridos, o que ocasiona motivação, satisfação em aprender.

O Construtivismo leva o educando a pensar, expandindo seu intelecto através de uma aprendizagem significativa, ou seja, que tenha sentido, e contextualizada. O conhecimento é construído a cada instante com a mediação do educador, respeitando o nível de desenvolvimento mental de cada educando.

Para Chauí (1980) "o diálogo do aluno é com o pensamento, com a cultura corporificada nas obras e nas práticas sociais e transmitidas pela linguagem e pelos gestos do professor, simples mediador".

Então, tanto no Construtivismo como na Pedagogia de Projetos, o educando é o próprio agente de seu desenvolvimento, o conhecimento é assimilado de maneira própria, mas sempre com o auxílio da mediação do educador. Aprender deixa de ser um simples ato de memorização e ensinar não significa mais repassar conteúdos prontos. O aluno deixa de ser um sujeito passivo, sempre a mercê das ordens do professor, lidando com um conteúdo completamente alienado de sua realidade e em situações artificiais de ensino-aprendizagem. Aprender passa então a ser um processo global e complexo, onde conhecer e intervir na realidade não se dissocia. O aluno é visto como sujeito ativo que usa sua experiência e conhecimento para resolver problemas.

Aprende-se participando, vivenciando sentimentos, tomando atitudes diante dos fatos, escolhendo procedimentos para atingir determinados objetivos. Ensina-se não só pelas respostas dadas, mas principalmente pelas experiências proporcionadas, pelos problemas criados, pela ação desencadeada (LEITE, 2000).

Suas concepções e conhecimentos prévios são levantados e analisados para que o educador possa problematizá-los e oferecer-lhes desafios que os façam avançar, atingindo o 
processo de equilíbrio/desequilíbrio que é a base do Construtivismo e ao mesmo tempo da Pedagogia de Projetos.

Então podemos dizer que a aprendizagem é o resultado do esforço de atribuir e encontrar significados para o mundo, o que implica a construção e revisão de hipóteses sobre o objeto do conhecimento, ela é resultado da atividade do sujeito, e o meio social tem fundamental importância para que ela ocorra, pois necessitamos de orientação para alcançá-la e aí surge a teoria do pensador russo Vygotsky sobre a Zona de Desenvolvimento Proximal que é a distância entre o nível de desenvolvimento real (conhecimento prévio, o que o indivíduo já sabe) e o nível de desenvolvimento potencial (onde ele pode chegar com a ajuda do outro), isto é, a possibilidade que o indivíduo (educando) tem de resolver problemas sob a orientação de outrem (educador).

\section{Aprender e ensinar por projetos}

O professor deve saber quais são suas atribuições e se identificar com elas, para que seu papel seja exercido com êxito. O uso de projetos requer um trabalho diferenciado por parte do professor. De acordo com Barbosa:

\footnotetext{
Os projetos demandam a criação de uma escuta atenta e de um olhar perspicaz, isto é, uma desenvolvida capacidade de observar, de escutar do docente para ver o que está circulando no grupo, quais os fragmentos que estão vindo à tona, quais os interesses e as necessidades do grupo. É preciso ainda conhecer e registrar os modos como cada criança se envolve e participa na construção dos conhecimentos propostos em um projeto. Essa observação é permeada pela subjetividade do educador, pois observar não é perceber a realidade, mas sim construir uma realidade. A análise dos registros ajuda a interpretar as mensagens que estão dando sentido para as crianças e significado para a vida do grupo. A pedagogia de projetos também possibilita tratar o trabalho docente como atividade dinâmica e não repetitiva. (BARBOSA, 2008, p.85)
}

O professor que opta em trabalhar com projetos deve a todo o momento fazer uma AÇÃO-REFLEXÃO-AÇÃO de sua prática pedagógica, pois é preciso se atualizar e atualizar sua maneira de ensinar. É possível mudar sua maneira de ensinar, mudando assim, sua história como profissional da educação.

Através do trabalho com projetos didáticos o professor divide tarefas com os alunos. Barbosa (2008, p. 86) afirma que "a vida cooperativa que se estabelece na sala de aula ajuda o 
professor a sair da sua solidão, já que ele passa a compartilhar tarefas, a coproduzir estratégias pedagógicas, a criar e a aprender". O professor promove assim um ambiente cooperativo e propício à aprendizagem.

A escolha do tema do projeto pode e até deve ser feita com os alunos, porém os professores devem ter a consciência que cabe a eles articular o tema do projeto escolhido com os conteúdos que devem ser trabalhados em sala de aula para a determinada série/idade. Portanto isso não é uma tarefa fácil, é preciso estudar e pesquisar para conseguir adaptar os conteúdos com o tema do projeto. Esse trabalho requer um planejamento ativo por parte do docente, pois ele não consegue planejar suas aulas com atividades que, por exemplo, ele aplicou no ano anterior, pois a cada ano os alunos mudam, mudando assim seus interesses, cada turma possui sua própria curiosidade e seu interesse em aprender algo novo. Segundo Barbosa:

\begin{abstract}
Ao professor cabe oferecer as estruturas narrativas da tradição, mas também observar a emergência do novo, conectar os conhecimentos da realidade dos alunos aos conhecimentos científicos, ser um articulador, um membro mediador que oferece os apoios indispensáveis, tal como os andaimes de Jerome Bruner, para que as crianças o utilizem na construção de seu processo, mas assim que possível possam dispensar a centralidade da presença do educador. Seu papel junto ao grupo será o de intermediar as ações das crianças e os objetos do conhecimento. (BARBOSA, 2008, p.87)
\end{abstract}

Cabe também ao professor ser mediador de conhecimentos e estimulador da aprendizagem. Portanto Antunes (2004, p. 20) afirma que "Outro importante papel do professor é colocar-se como um "fazedor de perguntas" levantando dúvidas, estabelecendo enigmas, propondo problemas, sugerindo desafios".

Para que seja então entendido o perfil e o papel do professor na adota o trabalho com projetos como uma estratégia pedagógica de ensino, Barbosa afirma que:

Portanto, o professor precisa aprofundar-se no conhecimento da sua matéria, precisa saber a história do seu campo de conhecimento, seus questionamentos atuais, suas fragilidades refinam os conhecimentos que tem sobre a estrutura da sua disciplina, atualizar os seus estudos, pois, quanto mais ele sabe, mais ele pode ensinar aos seus alunos uma postura de pesquisador quanto ao conteúdo que estuda. (BARBOSA, 2008, p.36)

A mediação do professor é fundamental, pois ao mesmo tempo em que o aluno precisa reconhecer a sua própria autoria no projeto, ele também precisa sentir a presença do professor que ouve, questiona e orienta, visando propiciar a construção de conhecimento do aluno. 
Id on Line Revista Multidisciplinar e de Psicologia

Id on Line Multidisciplinary and Psycology Journal

A mediação implica a criação de situações de aprendizagem que permitam ao aluno fazer regulações, uma vez que os conteúdos envolvidos no projeto precisam ser sistematizados para que os alunos possam formalizar os conhecimentos colocados em ação.

O trabalho por projeto potencializa a integração de diferentes áreas de conhecimento, assim como a integração de várias mídias e recursos, os quais permitem ao aluno expressar seu pensamento por meio de diferentes linguagens e formas de representação.

Do ponto de vista de aprendizagem no trabalho por projeto, Prado (2001) destaca a possibilidade de o aluno recontextualizar aquilo que aprendeu, bem como estabelecer relações significativas entre conhecimentos. Nesse processo, o aluno pode ressignificar os conceitos e as estratégias utilizadas na solução do problema de investigação que originou o projeto e, com isso, ampliar o seu universo de aprendizagem.

\section{Pedagogia de Projetos x Multi-Pluri-Trans-Interdisciplinaridade}

Em se tratando dos conteúdos, a pedagogia de projetos é vista pelo seu caráter de potencializar a interdisciplinaridade. Isto de fato pode ocorrer, pois o trabalho com projetos permite romper com as fronteiras disciplinares, favorecendo o estabelecimento de elos entre as diferentes áreas de conhecimento numa situação contextualizada da aprendizagem. No entanto, muitas vezes o professor atribui valor para as práticas interdisciplinares e com isso passa a negar qualquer atividade disciplinar. Essa visão é equivocada, pois Fazenda (1994) enfatiza que a interdisciplinaridade se dá sem que haja perda da identidade das disciplinas.

Nesse sentido, Almeida corrobora com estas ideias destacando:

“(..) que o projeto rompe com as fronteiras disciplinares, tornando-as
permeáveis na ação de articular diferentes áreas de conhecimento,
mobilizadas na investigação de problemáticas e situações da realidade.
Isso não significa abandonar as disciplinas, mas integrá-las no
desenvolvimento das investigações, aprofundando-as verticalmente em sua
própria identidade, ao mesmo tempo, que estabelecem articulações horizontais
numa relação de reciprocidade entre elas, a qual tem como pano de fundo a unicidade
do conhecimento em construção" (ALMEIDA, 2002, p.58).

O conhecimento específico - disciplinar - oferece ao aluno a possibilidade de reconhecer e compreender as particularidades de um determinado conteúdo, e o conhecimento integrado - 
Id on Line Revista Multidisciplinar e de Psicologia

Id on Line Multidisciplinary and Psycology Journal

interdisciplinar - lhe dá a possibilidade de estabelecer relações significativas entre conhecimentos. Ambos se realimentam e um não existe sem o outro.

Uma vez que a Pedagogia de Projetos, via de regra, está ligada à interdisciplinaridade, vale fazer umas rápidas definições sobre multi, pluri, trans e interdisciplinaridade, com suas variações sutis, mas relevantes distorções na prática. Apoiados em Nogueira (2001) Fazenda (1995), Hernández (1998), existem algumas conceituações:

a) Multidisciplinaridade: termo que pode ser utilizado quando da integração de diferentes conteúdos de uma mesma disciplina. Ex.: meio ambiente (água-ar-solo). Outra possibilidade será a justaposição de diferentes conteúdos de disciplinas distintas, sem preocupação de integração. Não existe uma prática cooperativa.

b) Pluridisciplinaridade: nessa prática já existem pequenos sinais de cooperação entre as diferentes disciplinas, mas os objetivos continuam distintos. Ex.: Copa do Mundo. Cada disciplina trabalha aspectos que lhe são inerentes, sem que haja correlação e integração. O conhecimento não foi integrado.

c) Transdisciplinaridade: nessa prática, bastante utópica, haveria uma proposta de sistema sem fronteiras entre as disciplinas, sendo impossível distinguir onde uma começa e outra termina. Conforme Fazenda (1995), este nível de abrangência negaria a possibilidade do diálogo, condição "sine qua non" para o exercício efetivo da interdisciplinaridade. Entretanto, Fernández (1998) percebe que a prática da pesquisa nas ciências e na tecnologia leva a efeito cada vez mais a transdisciplinaridade, no momento de organizar grupos e projetos de pesquisa; argumenta que essa realidade vem acontecendo na área biomédica, na ecologia, na paleontologia e etc. Entretanto, o autor reconhece a dificuldade de exercê-la adequadamente no contexto escolar, sem que se efetivem mudanças estruturais nas escolas e nos cursos de licenciatura.

d) Interdisciplinaridade: neste caso, a tônica é o trabalho de integração das diferentes áreas do conhecimento, um fazer pedagógico de cooperação e troca, aberto ao diálogo e ao planejamento. As diferentes disciplinas não aparecem de forma fragmentada e compartimentada, pois a problemática em questão levará à unificação. $\mathrm{Na}$ interdisciplinaridade existe uma coordenação (individual ou coletiva) que realiza as necessárias conexões. 
Id on Line Revista Multidisciplinar e de Psicologia

Id on Line Multidisciplinary and Psycology Journal

\section{Metodologia}

\section{Classificação da Pesquisa}

A pesquisa usada nesse artigo foi exploratória e foi desenvolvida através do levantamento bibliográfico necessário para o esclarecimento do tema.

De acordo com Gil (2007, p. 17), "Pode-se definir pesquisa como o procedimento racional e sistemático que tem como objetivo proporcionar respostas aos problemas que são propostos".

\section{Técnica de pesquisa para a coleta de dados}

Foi adotada neste trabalho a pesquisa bibliográfica em que, de acordo com Fachin (2006, p. 122) "uma das etapas é o levantamento dos livros, periódicos e demais materiais de origem escrita que servem como fonte de estudo e leitura".

Gil (2007, p. 44) reforça ainda esse conceito ao afirmar que "a pesquisa bibliográfica é desenvolvida com base em material já elaborado, constituído principalmente de livros e artigos científicos".

\section{Resultados e Discussão}

As discussões sobre Pedagogia de Projetos não são recentes e tem ganhado força à medida que se reflete sobre o papel da escola, sua função social e o significado das experiências escolares para aqueles que dela participam.

Os projetos apresentam-se como uma concepção de posturas pedagógicas e não meramente como uma técnica de ensino mais atrativa, possibilitando um ensino alicerçado no real e aberto às múltiplas relações que oportunizam ao aluno uma melhor compreensão da historicidade, bem como a sua formação como pessoa consciente do seu papel. 
Id on Line Revista Multidisciplinar e de Psicologia

Id on Line Multidisciplinary and Psycology Journal

No Brasil, o "Método de Projetos" tornou-se conhecido a partir da divulgação da "Escola Nova", que se colocava contra os princípios e métodos da escola tradicional. Como consequência, muitas escola passaram a utilizar o termo "Pedagogia de Projetos" para denominar as atividades diversificadas realizadas ao longo do ano letivo.

$\mathrm{Na}$ revisão de literatura, os autores corroboram com a ideia de projeto como uma "atitude didática", também defendida por John Dewey, um dos representantes da "Pedagogia Ativa" e precursor da pedagogia de projetos. Os estudos acerca da aplicabilidade da pedagogia de projetos nas redes de ensino trazem alguns dos fatores associados a sua execução.

Majoritariamente, um projeto se constitui como:

\begin{abstract}
Um novo desafio para o professor pode viabilizar ao aluno um modo de aprender baseado na integração entre conteúdos das várias áreas do conhecimento, bem como entre diversas mídias (computador, televisão, livros) disponíveis no contexto da escola (PRADO, 2009, p.14).
\end{abstract}

Nos trabalhos de Mourão \& Martinez (2006), retrata-se as contradições vividas na prática com projetos, configurando-se como uma situação potencial de desenvolvimento da criatividade, seja por parte do aluno, seja por parte do professor.

Para Prado (2009),

\begin{abstract}
"os novos desafios educacionais ainda não se encaixam na estrutura do sistema de ensino, que mantém uma organização funcional e operacional, como, por exemplo, horário de aula de 50 minutos e uma grade curricular sequencial que dificulta o desenvolvimento de projetos que envolvam ações interdisciplinares, que contemplem o uso de diferentes mídias disponíveis na realidade da escola e impliquem aprendizagens que extrapolam o tempo da aula e o espaço físico da sala de aula e da escola.” (PRADO, 2009, p.14)
\end{abstract}

Tais contrapontos também foram citados no texto de Oliveira \& Venturos (2005) quando apresentam a utilização de projeto como uma práxis pedagógica que conduz para os ambientes de aprendizagem mais prazerosos, envolventes, produtivos e flexíveis.

A formação do professor é tida como um dos fatores que influenciam na implementação da pedagogia de projetos. Para vários autores, o professor é visto como um facilitador no processo de busca no conhecimento que deve partir do aluno. Cabe a ele organizar e coordenar as situações de aprendizagens, adaptando suas características individuais dos alunos para desenvolver suas capacidades e habilidades. 
Id on Line Revista Multidisciplinar e de Psicoloqia

Id on Line Multidisciplinary and Psycology Journal

Na pesquisa de Fleck (2007) e de Prado (2009), fala-se na necessidade de abertura e flexibilidade para relativizar a prática docente e as estratégias pedagógicas com vistas a propiciar ao aluno a reconstrução do conhecimento.

Outro fator que corresponde a uma dificuldade de implementação dos projetos é a política pedagógica das instituições de ensino. Nos estudos de Lopes (2012) aborda-se que:

\footnotetext{
"Muitas vezes algumas instituições nem possuem um plano político pedagógico o que acaba por dificultar a implementação de inovações na escola, outras vezes algumas instituições possuem uma política pedagógica tradicional o que acaba por podar a ação do professor dentro de sala de aula" (LOPES, 2012).
}

Dentre os pontos mais relevantes acerca do tema, está a necessidade de pesquisa e divulgação desta prática pedagógica para que sela melhor compreendida e utilizada pela comunidade escolar. De acordo com Prado (2009), "a formalização pode propiciar a abertura para um novo ciclo de ações num nível mais elaborado de compreensão dando, portanto, o formato de uma espiral ascendente, representando o mecanismo do processo de aprendizagem" (p.17).

\section{Considerações Finais}

Romper com o modelo tradicional de ensino, visando o desenvolvimento da aprendizagem com a participação ativa dos alunos dentro da proposta da pedagogia de projetos a qual estabelece uma aprendizagem significativa, é sem duvida uma possível solução para que o ensino consiga vencer com os antigos paradigmas da educação.

Assim, faz-se necessário que o campo educacional tenha um olhar inovador para que possa haver as mudanças na forma de ensinar, priorizando a formação de cidadãos críticos, reflexivos, participativos e conscientes de suas decisões, estabelecendo uma sociedade justa e consciente dos seus direitos e deveres.

A Pedagogia de Projeto se insere nessa postura, exigido dos sujeitos que a assume uma nova forma de conceber a educação escolar: mais flexível e aberta. Para isso, é necessário que os professores que assumem essa postura, enfrentem o desafio de superar uma cultura escolar 
Id on Line Revista Multidisciplinar e de Psicologia

Id on Line Multidisciplinary and Psycology Journal

fragmentada na qual foram formados, como alunos e como professores, passando a ser exigido um novo modelo de formação, onde não haja uma dicotomia entre formação e ação, entre discurso e prática.

Portanto se o objetivo da educação está fundamentada no desenvolvimento da capacidade de raciocínio e espírito crítico do individuo é fundamental que o ensino adquira uma nova prática, com novos olhares e horizontes oportunizando esse conhecimento aos seus alunos.

\section{Referências}

ALMEIDA, F. J. \& FONSECA JÚNIOR, F.M. Projetos e ambientes inovadores. Brasília: Secretaria de Educação a Distância - SEED/ Proinfo - Ministério da Educação, 2000.

ALMEIDA, M.E.B. de. Como se trabalha com projetos (Entrevista). Revista TV ESCOLA. Secretaria de Educação a Distância. Brasília: Ministério da Educação, SEED, nº 22, março/abril, 2002.

Educação, projetos, tecnologia e conhecimento. São Paulo: PROEM, 2002.

ANTUNES, Celso. Projetos e práticas pedagógicas na educação infantil. Petrópolis, RJ: Vozes, 2012.

ANTUNES, Celso. Um método para o ensino fundamental: O projeto. Petrópolis, RJ: Vozes, 2004.

BARBOSA, Maria Carmen Silveira. Projetos Pedagógicos na educação infantil. Porto Alegre, RS: Artmed, 2008.

BRASIL. Lei de Diretrizes e Bases na Educação Nacional - LDB N 9394/96. Brasília: MEC, 1996.

CHAUI, Marilena de Souza. Ideologia e Educação in revista Educação e Sociedade n. 5. São Paulo: Cortez Editora/Autores Associados, 1980.

FACHIN, Odília. Fundamentos de metodologia. São Paulo, SP: Saraiva, 2006.

FAZENDA, Ivani C. A. A Interdisciplinaridade: um projeto em parceria. 3. Ed. São Paulo: Loyola, 1995.

FLECK, Maria Luiza Steiner. Pedagogia de Projetos: o princípio, o fim e o meio. Diálogo, Canoas, n. 11, p.117-140, 2007. Semestral. Disponível em: 
Id on Line Revista Multidisciplinar e de Psicologia

Id on Line Multidisciplinary and Psycology Journal

<http://biblioteca.unilasalle.edu.br/docs_online/artigos/dialogo/2007_n11/mlsfleck.pdf>. Acesso em: 13 set. 2015.

FREIRE, Paulo. Pedagogia do oprimido. 36a ed. São Paulo: Paz e Terra, 1987. 184p.

FREIRE, F.M.P. \& PRADO, M.E.B.B. Projeto Pedagógico: Pano de fundo para escolha de um software educacional. In: J.A. 1999.

GIL, Antonio Carlos. Como elaborar Projetos de Pesquisa. São Paulo, SP:

Atlas S.A., 2007.

HERNÁNDEZ, Fernando. Transgressão e mudança na educação: os projetos de trabalho; trad. Jussara Haubert Rodrigues. Porto Alegre: Artes Médicas, 1998.

LEITE, L.H.A. Pedagogia de Projetos: Intervenção no Presente. Presença Pedagógica, Belo Horizonte: Dimensão , v. 2, n. 8, p. 25 - 33, mar/abr 1996.

LEITE, Lucia Helena Alvarez; MENDEZ, Verônica. Os Projetos de Trabalho: Um espaço para viver a diversidade e a democracia na escola. Revista de Educação, Porto Alegre: Projeto, ano 3, n.4, p.25-29, jan./jun. 2000.

LOPES, Rovena Monteiro. A Pedagogia de Projetos. 2012. Disponível em: $<\mathrm{http}$ //pedagogiaaopedaletra.com/resumo-a-pedagogia-de-projetos/>. Acesso em: 13 set. 2015.

MACHADO, N. J. Educação: Projetos e valores. São Paulo: Escrituras Editora, 2000.

MOURA, Daniela Pereira de. Pedagogia de Projetos: Contribuições para Uma Educação Transformadora, 2010. Disponível em $<$ http://www.pedagogia.com.br/artigos/pedegogiadeprojetos/index.php?pagina=0 $>$ Acesso em $31 / 08 / 15$.

MOURÃO, Renata F.; MARTÍNEZ, Albertina M.. A criatividade do professor: a relação entre o sentido subjetivo da criatividade e a pedagogia de projetos. Revista Semestral da Associação Brasileira de Psicologia Escolar e Educacional (ABRAPEE), São Paulo, v. 10, n. 2, p.263-272, 2006. Semestral. Disponível em:

<http://www.scielo.br/scielo.php?script=sci_arttext\&pid=S1413-85572006000200009>. Acesso em: 13 set. 2015.

NOGUEIRA, Nilbo Ribeiro. Pedagogia dos Projetos: uma jornada interdisciplinar rumo ao desenvolvimento das múltiplas inteligências. São Paulo, Editora Érica, 2001.

OLIVEIRA, Leandra Martins de; VENTURA, Paulo Cezar Santos. A prática da aprendizagem por projetos em três óticas distintas. Educ. Tecnol., Belo Horizonte, v. 10, n. 3, p.22-28, 2005. Semestral. Disponível em:

<http://www.nacional.edu.br/grupodeestudos/docs/artigo_pedagogia_projetos_1.pdf >Acesso em: 13 set. 2015 . 
PRADO, M.E.B.B. Articulando saberes e transformando a prática. Boletim do Salto para o Futuro. Série Tecnologia e Currículo, TV ESCOLA. Brasília: Secretaria de Educação a Distância - SEED. Ministério da Educação, 2001.

PRADO, Maria Elisabette Brisola Brito. Pedagogia de projetos: fundamentos e implicações. In: ALMEIDA, Maria Elizabeth Bianconcini de; MORAN, José Manuel (Org.). Integração das tecnologias na educação. Brasília: Ministério da Educação/SEED/TV Escola/Salto para o Futuro, 2005. cap. 1, artigo 1.1, p. 12-17. Disponível em: < http://www.pucrs.br/famat/viali/tic_literatura/livros/Salto_tecnologias.pdf >. Acesso em: 13 set. 2015

ZABALA, A. A prática educativa: como ensinar. Porto Alegre, RS: ArtMed, 1998.

Como citar este artigo (Formato ABNT):

GUEDES, J.D.; SOUZA, A.S.; SIDRIM, F.M.L.; LIMA, Q.F.O. Pedagogia de Projetos: Uma ferramenta para a Aprendizagem. Id on Line Revista Multidisciplinar e de Psicologia, Janeiro de 2017, vol.10, n.33, Supl 2. p. 237-256. ISSN: 1981-1179.

Recebido: 10/01/2017

Aceito: 17/01/2017 